\title{
Co-working Space as a Creative-Collaborative Space of Community CENTRe in PURWOKerto
}

\section{Ruang Co-working untuk Kolaborasi Kreatif pada Pusat Komunitas Kreatif di PURWoKerto}

\author{
Leny Indah Sari ${ }^{*}$, Ofita Purwani², Leny Pramesti ${ }^{3}$ \\ Program Studi Arsitektur, Fakultas Teknik, Universitas Sebelas Maret Surakarta ${ }^{1}$ \\ lenyindah@student.uns.ac.id* \\ Program Studi Arsitektur, Fakultas Teknik, Universitas Sebelas Maret Surakarta ${ }^{2}$ \\ Program Studi Arsitektur, Fakultas Teknik, Universitas Sebelas Maret Surakarta ${ }^{3}$
}

\begin{abstract}
This paper concerns about Designing Community Centre in Purwokerto as Creative-Collaborative space by using co-working space. Co-working space is one way to induce creative ideas, because it makes it possible for people to share and learn together with other people from different background. This space also anables people to connect and collaborate to create ideas.

As Purwokerto is one of the cities in Indonesia whose concern about developing its creative communities, this city has a potential to be the locus for the Community Centre. This article will then focus on the designing of the Community Centre by using co-working space for inducing creative and collaborative activities in Purwokerto. Some key aspects of co-working space to be applied in the design are the services, spatial layout and ambience of space.
\end{abstract}

Keywords: co-working, collaboration, the elements of space, ambience of space.

\section{PENDAHULUAN}

Sejak munculnya Program Masyarakat Ekonomi ASEAN pada tahun 2015, Indonesia menjadi salah satu negara yang berkembang pesat di bidang ekonomi. Ekonomi Kreatif di Indonesia berkontribusi 7.38 persen dari total ekonomi nasional Indonesia (Bekraf, 2017).

Ekonomi Kreatif adalah salah satu sektor yang diharapkan dapat menjadi kekuatan ekonomi yang untuk masa depan mengingat sumber daya alam yang semakin menurun. Badan Ekonomi Kreatif (Bekraf) merupakan badan non kementrian Indonesia yang berfokus pada kegiatan Ekonomi Kreatif di Indonesia. Bekraf memiliki enam belas subsektor yang bertujuan untuk mengembangkan industri kreatif di Indonesia (Bekraf, 2017).

Sejak saat itu, banyak muncul start-up kreatif dan penggiat komunitas-komunitas kreatif sebagai fenomena baru dalam berbisnis pada jaman sekarang. ASEAN memiliki lebih dari
7000 start-up dan lebih dari 2000 diantaranya merupakan warga negara Indonesia (rappler.com).

Kemunculan start-up kreatif dan penggiat komuntias kreatif di Indonesia yang terus bertambah menjadikan beberapa kota besar di Indonesia menyediakan sarana yang dapat digunakan untuk berkolaborasi bagi para startup kreatif dan komunitas penggiat kreatif.

Berkembangnya komunitas kreatif dan pembangunan kota yang cukup pesat menjadikan banyak kota-kota besar maupun berkembang yang ada di Indonesia menciptakan sarana dalam mengembangkan kreativitas dan inovasi pemudanya. Salah satunya adalah kota yang terus melakukan perkembangannya yaitu Purwokerto.

Beberapa acara kreatif telah diselenggarakan oleh pihak pemerintah Purwokerto. Salah satunya adalah 'Festival Krenova Banyumas Keren!' yang merupakan kegiatan kolaborasi 
Pemerintah Daerah yang dimotori oleh BAPPEDA Kabupaten Banyumas dengan banyak komunitas dan sektor swasta. Program festival tersebut merupakan sebuah acara yang diselenggarakan dalam mengoptimalkan partisipasi dan kerjasama stakeholders dan masyarakat dalam proses Perencanaan Pembangunan (Laporan Kinerja Instansi Pemerintah Bappeda Kabupaten Banyumas Tahun 2016).

Purwokerto menjadi salah satu kota yang diperhitungkan dalam mengembangkan kreativitas dan inovasi para pemudanya. Para start-up kreatif dan penggiat komunitas kreatif di Purwokerto ini membutuhkan sarana yang dapat mendukung kegiatan kreativitasnya.

Adanya Pusat Komunitas Kreatif di Purwokerto merupakan sarana yang diharapkan dapat mendukung kegiatan dan pengembangan kreativitas masyarakat Purwokerto. Salah satu yang menjadi bagian dari fasilitas yang disediakan oleh sarana ini adalah ruang co-working. Adanya ruang coworking merupakan sarana yang dapat menciptakan kegiatan kolaborasi kreatif oleh para start-up kreatif maupun komunitas penggiat kreatif di Purwokerto.

Co-working merupakan sebuah tipologi area kerja yang dapat mengubah cara seseorang dalam bekerja. Co-working dapat terjadi apabila di dalamnya terdapat lingkungan dan jaringan yang saling terikat antar pengguna menjadi sebuah komunitas (Merkel, 2015).

Para start-up kreatif dan penggiat komunitas kreatif biasanya merupakan seseorang atau kelompok yang bekerja secara mandiri dan bekerja secara nomaden (remote workers). Semakin bertambahnya pekerja mandiri, maka semakin banyak dan berkembang sarana yang dibutuhkan untuk mewadahi kegiatan para pekerja mandiri tersebut.

Ruang co-working merupakan sarana yang dapat mewadahi kegiatan para pekerja mandiri tersebut di mana para pekerja dapat mengerjakan pekerjaannya secara mandiri tetapi paralel dalam satu tempat bersama dengan pekerja lainnya yang memiliki perbedaan latar belakang (Garrett, Arbor, \& Spreitzer, 2014).

Sebuah survey yang di lakukan oleh Coworking Indonesia bekerjasama dengan $\mathrm{Lab}$ Kinetic, terdapat empat fokus utama antara lain komunitas $(74,2 \%)$, teknologi $(67,7 \%)$, bisnis
$(67,7 \%)$, dan kewirausahaan sosial $(64,5 \%)$. Sasaran pengguna co-working space diantaranya start-up digital, pekerja lepas, komunitas, mahasiswa, wirausahawan, dan pelaku industri kreatif (recap.id, 2017).

Secara fisik, co-working merupakan sarana yang menyediakan beragam wawasan tentang bagaimana menyatukan kualitas hubungan sosial dengan kegiatan bekerja (Garrett et al., 2014).

Faktor spasial menjadi hal yang penting dalam mewujudkan kualitas lingkungan pada Ruang co-working. Faktor-faktor tersebut di antaranya adalah keterbukaan, meminimalisasi aturan dalam suatu area dan teritorial yang mempengaruhi interaksi sosial dan kolaborasi (Soediono, 2015).

Kolaborasi menjadi potensi yang sangat penting dalam mewadahi interaksi sosial yang secara tidak disengaja merupakan pertemuan antara orang-orang yang bertalenta dan kreatif, kemudian saling berbagi pengetahuan pada satu ruang (Spinuzzi, 2012). Keterbukaan dalam berbagi pengetahuan dan menerima perbedaan latar belakang dari setiap pengguna di dalamnya mempengaruhi tata letak dan suasana pada ruang co-working.

Arsitektur dapat mewujudkan kualitas lingkungan pada area co-working yang dapat menciptakakan kegiatan interaktif dan kolaboratif antar pekerja yang memiliki perbedaan latar belakang (Paper, 2016). Desain arsitektur secara inklusif menjadi penyusun tumbuhnya lingkungan sosial tersebut (sense of community) pada suatu ruang co-working. Sifat ruang, pencahayaan, warna dan material merupakan elemen pembentuk ruang (Wicaksono \& Tisnawati, 2014) yang paling terlihat secara visual yang dapat menciptakan atmosfir dan suasana pada ruang (Paper, 2016).

\section{METODE}

Metode yang digunakan dalam menciptakan kegiatan interaktif dan kolaboratif serta menciptakan atmosfir dan suasana ruang secara visual pada ruang co-working sebagai bagian dari Pusat Komunitas Kreatif di Purwokerto adalah sebagai berikut. 


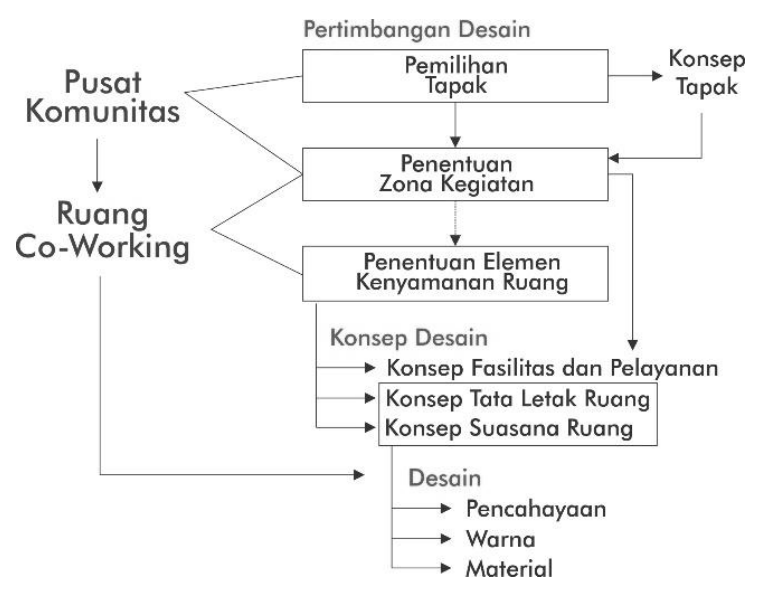

Bagan 1. Metode Desain

Pada bagan di atas, Pusat Komunitas dan Ruang co-working merupakan objek yang menjadi fokus. Berikut merupakan metode desain ruang co-working.

1. Menentukan Pertimbangan Desain

Menentukan pertimbangan desain dalam menciptakan ruang co-working sebagai bagian dari Pusat Komunitas merupakan langkah pertama yang dilakukan untuk menentukan fokus dan batasan yang akan digunakan pada desain. Menentukan Pertimbangan desain berlandaskan studi observasi ruang co-working dan studi literatur tentang kenyamanan ruang pada ruang co-working.

2. Menentukan Konsep

Menentukan Konsep merupakan penerapan pada Pusat Komunitas dan ruang co-working yang menjadi bagiannya yang dilakukan berdasarkan pertimbangan yang telah dilakukan sebelumnya.

3. Desain

Desain merupakan hasil dari penerapan konsep yang telah dilakukan. Konsep yang tersebut diterapkan pada tiga elemen dasar penciptaan ruang yaitu Dinding, Lantai, dan Plafon.

\section{HASIL DAN PEMBAHASAN}

\section{PERTIMBANGAN DESAIN}

Terdapat beberapa konsep yang mempertimbangkan kegiatan dan pelayanan dalam menciptakan kegiatan co-working sebagai bagian dari Pusat Komunitas di Purwokerto diantaranya:

\section{Pemilihan Tapak}

Pemilihan tapak dilakukan berdasarkan intensitas masyarakat dalam melakukan kegiatan kreatif di Purwokerto. Pelaku kegiatan-kegiatan kreatif sebagian besar merupakan pemuda yang masih memiliki produktivitas yang tinggi dan keingintahuan yang besar dalam berwawasan. Sarana pendidikan, taman kota (area publik) dan kedai kopi menjadi titik kumpul pelaku kegiatan kreatif. Penentuan tapak terpilih dilakukan dengan melakukan pemetaan dengan memertimbangkan sarana-sarana tersebut. Selain itu, aksesibilitas juga menjadi hal yang akan dipertimbangkan untuk kemudahan pencapaian.

\section{Zona Kegiatan}

Zona Kegiatan sangat dipengaruhi oleh pengguna dalam menggunakan fasilitas maupun pelayanan yang sesuai dengan kegiatan yang dilakukan. Zona kegiatan juga dipengaruhi oleh tata letak ruang sesuai dengan kegitan yang bersifat aktif (ruang gerak) maupun pasif (ruang diam). (Wicaksono \& Tisnawati, 2014)

\section{Kenyamanan Ruang}

Kenyamanan ruang co-working sangat dipengaruhi oleh fasilitas maupun pelayanan yang ada didalamnya dan terciptanya tata letak ruang serta suasana ruang dalam. (Marcelina, Ardana, Yong, \& Siwalankerto, 2016).

Aspek-aspek pencipta kenyamanan ruang yang telah dijelaskan tersebut dijabarkan melalui hasil observasi maupun studi literartur sebagai berikut.

a. Fasilitas dan Pelayanan

Ruang co-working bukan hanya sekedar konsep ruang, namun layanan dan fasilitas tetap menjadi salah satu yang perlu dicermati. Penerapan layanan pada beberapa ruang coworking menggunakan sistem sewa ruang dengan memberikan tambahan fasilitas yang mendukung aktivitas para pekerja mandiri, komunitas maupun para perusahaan rintisan (start-up).

Mengenali dan mempelajari pelayanan pada ruang co-working dilakukan dengn melakukan observasi pada beberapa ruang co-working yang ada di Indonesia. Berikut 
merupakan hasil observasi yang dilakukan pada 4 co-working di Indonesia.

Tabel 1. Palayanan Ruang Co-working

\begin{tabular}{|c|c|}
\hline $\begin{array}{l}\text { Ruang Co- } \\
\text { working }\end{array}$ & Pelayanan yang disediakan \\
\hline $\begin{array}{l}\text { Co \& Co } \\
\text { Space } \\
\text { (Bandung) }\end{array}$ & $\begin{array}{l}\text { - Keanggotaan / Membership ( } \\
\text { Common, Team, Resident.) } \\
\text { - Lepas / Passes ( Weekly Pass, } \\
\text { Daily Pass, } 6 \text { Hours Pass, } 3 \\
\text { Hours Pass) }\end{array}$ \\
\hline $\begin{array}{l}\text { Impala } \\
\text { Space } \\
\text { (Semarang) }\end{array}$ & $\begin{array}{l}\text { - Daily, Weekly, Half Month, } \\
\text { Full Month. }\end{array}$ \\
\hline $\begin{array}{l}\text { Hubud } \\
\text { (Bali) }\end{array}$ & $\begin{array}{l}\text { - Event } \\
\text { - Casual (30 jam per bulan) } \\
\text { - In and Out (50 jam per bulan) } \\
\text { - Pro ( } 100 \text { jam per bulan) } \\
\text { - Unlimited (unlimited) } \\
\text { - Night Owl (jam } 6 \text { petang - } 8 \\
\text { pagi) } \\
\text { - Day Pass ( } 24 \text { jam per bulan) }\end{array}$ \\
\hline $\begin{array}{l}\text { Coworkinc } \\
\text { (Jakarta) }\end{array}$ & $\begin{array}{l}\text { - Individu (Walk-in, Day Pass, } 3 \\
\text { Days Pass, } 10 \text { Days Pass, Half } \\
\text { Moth, Full Month. } \\
\text { - Kelompok (Meeting Room) }\end{array}$ \\
\hline
\end{tabular}

b. Tata Letak Ruang

Aktivitas atau kegiatan merupakan hal yang mempengaruhi adanya sifat ruang. Terdapat dua jenis sifat ruang yaitu (Wicaksono \& Tisnawati, 2014).

1) Ruang Gerak

Ruang gerak merupakan sifat ruang yang memiliki kegiatan yang dinamis. Pergerakan kegiatan sangat mempengaruhi sirkulasi yang dibutuhkan

2) Ruang diam.

Ruang diam merupakan sifat ruang yang memiliki kegiatan yang statis. Kegiatan tersebut tidak memiliki banyak pergerakan sehingga sirkulasi yang dibutuhkan merupakan sirkulasi yang secukupnya.

Penciptaaan tata letak (layout) ruang dalam bekerja, menyesuaikan dengan kegiatan yang sesuai. Terdapat sembilan jenis generik ruang kerja sebagai berikut. (Marcelina et al., 2016)

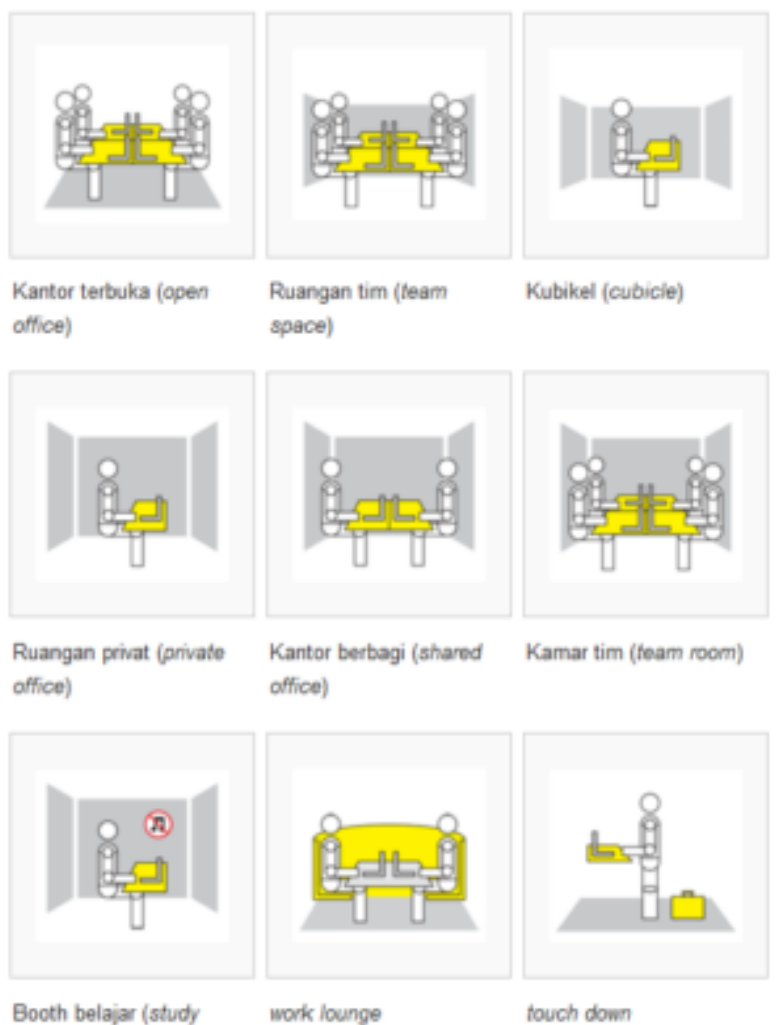

Gambar 1. Jenis Generik Ruang Kerja (Sumber: (Marcelina et al., 2016)

\section{c. Suasana Ruang}

Setiap ruang, penting untuk memiliki keseimbangan yang baik dari masingmasing elemen pembentuk ruang. Harmonisasi dan keseimbangan dapat dicapai dengan menerapkan gabungan beberapa elemen dasar (Hidjaz \& Interior, n.d.).

Elemen dasar yang akan digunakan dalam menciptakan ruang co-working merupakan elemen dasar yang dapat ditangkap secara kasat mata oleh pengguna. Penggabungan beberapa elemen dasar tersebut antara lain:

1) Pencahayaan

Cahaya mempengaruhi penataan ruang dalam hal menentukan atmosfir ruang, mempengaruhi suasana hati pengguna, dan mendukung fungsi ruang. Terdapat beberapa jenis pencahayaan sebagai berikut.

a) General Lighting: sistem penyinaran yang menjadi sumber penerangan utama. Pencahayaan secara tak langsung akan menghasilkan cahaya yang merata tanpa membuat silau dan memiliki suasana yang lebih hangat. 
Keterangan

: Stasiun Purwokerto

: Alun-alun Purwokerto

O : SMAN 2, SMPN 6, SMAN 1, SMK 1.

0 : Universitas Jenderal Soedirman

: GOR Satria

: Pangkalan Angkutan Kota (Palma)

0 : Pusat Perbelanjaan

b) Task Lighting: sistem pencahayaan yang difokuskan pada suatu tempat dengan tujuan membantu kegiatan tertentu. Digunakan pada ruang kerja yang dilengkapi lampu meja untuk membaca agar mata tidak jenuh saat membaca.

c) Accent Lighting: untuk memfokuskan suatu benda agar dapat lebih terlihat. Accent Lighting menggunakan spotlight sebab dapat menghasilkan cahaya yang kuat dan menghasilkan fokus pada sebuah objek yang dituju.

2) Warna

Semua warna dapat menimbulkan efek psikologis tertentu terhadap orang yang melihatnya. Setip warna dapat menimblkan kesan yang berbeda-beda pada sebuah ruang. Menurut buku Color Harmony oleh Hideaki Chijiwa, setiap warna memiliki karakteristik yang dapat digolongkan menjadi enam golongan (Komunikasi, Dan, Kerja, \& Bott, 2014) yaitu,

a) Warna hangat yaitu warna-warna yang terletak antara merah dan kuning, yaitu merah, kuning, coklat dan jingga.

b) Warna sejuk yaitu warna yang terletak antara hijau dan ungu melalui biru.

c) Warna tegas yaitu warna biru, merah, kuning, hitam dan putih.

d) Warna tua/berat yaitu warna-warna tua yang mendekati warna hitam.

e) Warna muda/ringan yaitu warna-warna yang mendekati warna putih.

f) Warna tenggelam yaitu warna yang diberi campuran kelabu.

3) Material

Setiap bahan atau material memiliki sifat dan karakter yang berbeda-beda dan secara langsung akan mempengaruhi persepsi seseorang (Komunikasi et al., 2014). Kesan yang ditimbulkan oleh setiap bahan atau material akan dijabarkan sebagai berikut:
Tabel 2. Kesan yang ditimbulkan oleh Material

\begin{tabular}{|l|l|}
\hline Material & Kesan yang ditimbulakan \\
\hline Kayu & $\begin{array}{l}\text { Hangat, Lunak, Alamiah, } \\
\text { Menyegarkan. }\end{array}$ \\
\hline Batu Bata & $\begin{array}{l}\text { Praktis, luas, sejuk, } \\
\text { sederhana. }\end{array}$ \\
\hline Semen & Dekoratif \\
\hline Batu Alam & $\begin{array}{l}\text { Alami, sederhana, } \\
\text { informal. }\end{array}$ \\
\hline Marmer & $\begin{array}{l}\text { Mewah, kuat, formal, } \\
\text { agung. }\end{array}$ \\
\hline Beton & $\begin{array}{l}\text { Formal, } \\
\text { kokoh. }\end{array}$ \\
\hline Baja & Keras, kokoh, kasar. \\
\hline Metal & Ringan, dingin. \\
\hline Kaca & Ringan, dingin, dinamis. \\
\hline Plastik & Ringan, dinamis, informal. \\
\hline Bambu & $\begin{array}{l}\text { Sederhana, ringan, alamiah, } \\
\text { kuat. }\end{array}$ \\
\hline & Sumber: Komunikasi et al., 2014
\end{tabular}

\section{KONSEP}

Pusat Komunitas Kreatif berada di kawasan yang terdapat banyak kegiatan-kegiatan kreatif di sekitarnya sesuai dengan pertimbangan yang telah dilakukan sebelumnya. Tapak terpilih untuk Pusat Komunitas Kreatif di Purwokerto terdapat di kawasan sepanjang Jalan Jendral Soedirman Purwokerto yang merupakan Jalan Arteri Primer Kota. Kawasan tersebut terdapat beberapa titik kumpul kegiatan kreatif seperti Alun-Alun Purwokerto, Pusat Perbelanjaan, kedai kopi di sepanjang jalan dan beberapa sekolah yang letaknya berdekatan dengan Jalan Jendral Soedirman.

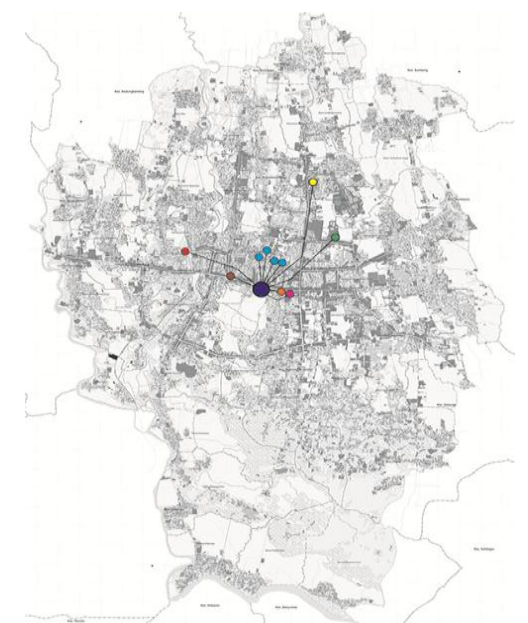

Gambar 2. Jangkauan Tapak Terpilih dengan Titik Kumpul Kegiatan Kreatif 
Kondisi tapak terpilih merupakan tapak bekas penggunaan Stasiun Timur Purwokerto. Tapak tersebut merupakan tanah kosong yang disewakan untuk ruko pada bagian tepi tapak yang menghadap Jalan Raya Jendral Soedirman. Tapak tersebut berbatasan dengan kawasan perkantoran, ruko, dan permukiman warga. Berikut merupakan kondisi sekitar tapak terpilih.

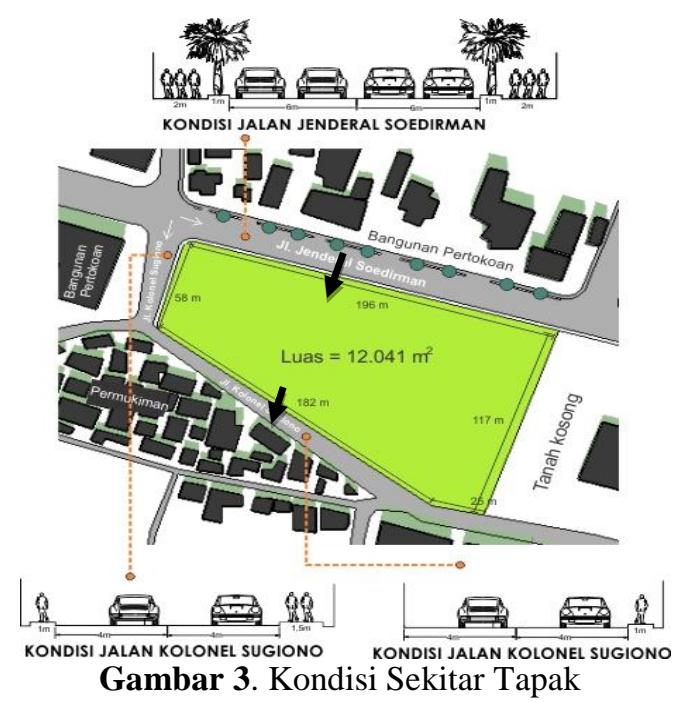

Kondisi tapak terpilih merupakan tapak bekas penggunaan Stasiun Timur Purwokerto. Tapak tersebut merupakan tanah kosong yang disewakan untuk ruko pada bagian tepi tapak yang menghadap Jalan Raya Jendral Soedirman. Tapak tersebut berbatasan dengan kawasan perkantoran, ruko, dan permukiman warga. Berikut merupakan kondisi sekitar tapak terpilih.

Entrance masuk tapak melalui Jalan Jendral Soedirman dan keluar melalui Jalan Kolonel Sugiono.

Tapak terpilih dan penentuan entrance pada pada tapak digunakan sebagai pertimbangan dalam mementukan zona pada Pusat Komunitas.
Penciptaan konsep ruang pada dari Pusat Komunitas Kreatif di Purwokerto didasarkan pada pelayanan yang ditawarkan sesuai sifat ruang. Penerapan sifat ruang ini kemudian menentukan zona dan program peruangan berdasarkan studi literasi dengan menerapkan batasan-batasan yang sesuai.

Pusat Komunitas Kreatif di Purwokerto merupakan sebuah sarana yang dapat digunakan oleh masyarakat secara umum dan penggiat kreatif setempat. Pusat Komunitas Kreatif di Purwokerto terbagi menjadi dua lantai. Lantai satu merupakan zona kegiatan yang dilakukan oleh masyarakat secara umum dan terdapat beberapa fasilitas yang mendukung adanya kegiatan kreatif di Purwokerto. Lantai dua merupakan ruang yang yang disedikan untuk bertukar pikiran dengan sesama start-up kreatif atau penggiat kreatif. Secara khusus, lantai dua merupakan ruang coworking yang disediakan untuk pengguna yang menggunakan sesuai pelayanan yang telah di sediakan. Penentuan zona pada setiap lantai dipengaruhi oleh jenis pengguna, kegiatan dan pelayanan yang disediakan.

Berikut merupakan zona kegiatan yang di sediakan ruang co-working pada Pusat Komunitas di Purwokerto.

Keterangan:

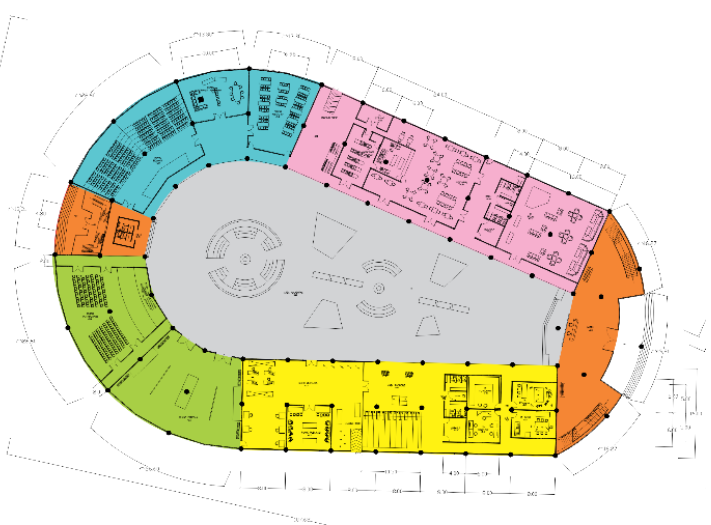

Gambar 4. Zona Kegiatan Lantai 1

$\square$, : Zona Edukasi
$\square$, :ona Penerimaan
: Zona Apresiasi
$\square$, : Zona Sharing
$\square$, : Zona Rekreasi
$\square$, : Zona Kolaborasi


Leny Indah, Ofita Purwani, Leny Pramesti, Co-Working Space as...

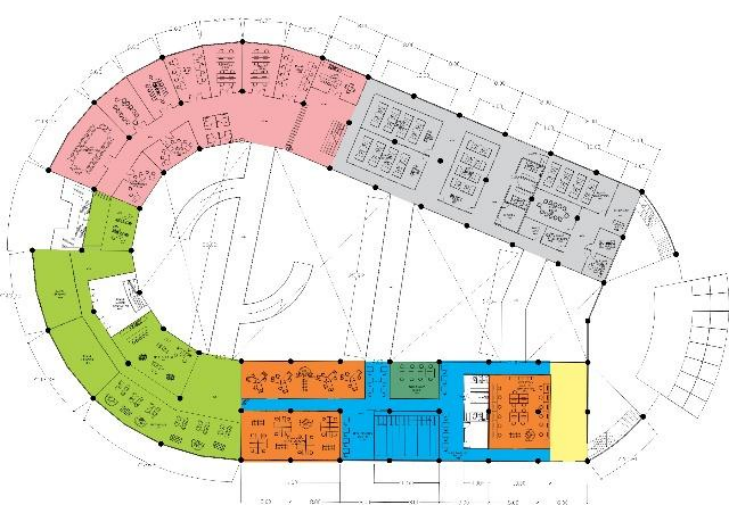

\begin{tabular}{|c|c|c|c|}
\hline Fasilitas & Pencahayaan & Warna & Material \\
\hline Meja Kerja (non komputer) & General Lighting & & Hangat, Sederhana \\
\hline Meja Kerja (komputer) & General \& Down & & Hangat, \\
\hline Ruang Pertemuan & General Lighting & & Hangat, Formal \\
\hline Game Station & General \& Down & & Hangat, Sederhano \\
\hline Self Service Area & $G$ & & Inform \\
\hline Discussion Lounge & $\begin{array}{l}\text { General \& Down } \\
\text { Lighting }\end{array}$ & & Informal \\
\hline Privat Room & General Lighting & & $\begin{array}{l}\text { Hangat, Sederho } \\
\text { Informal }\end{array}$ \\
\hline
\end{tabular}

Keterangan:

Bagan 4. Konsep Suasana Ruang

\section{DESAIN}

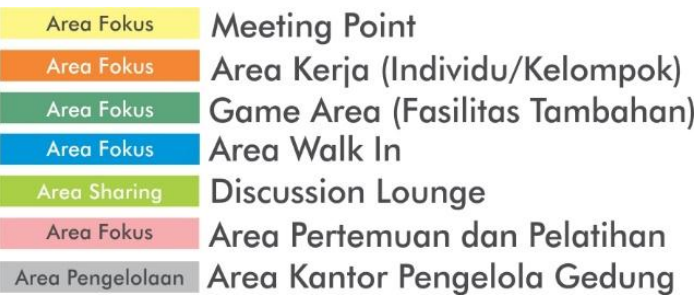

Gambar 4. Zona Kegiatan Lantai 2

Pelayanan yang diterapkan pada perancangan ruang co-working pada Pusat Komunitas Kreatif di Purwokerto adalah penerapan sistem sewa untuk individu maupun kelompok. Untuk individu diterapkan sistem sewa dengan konsep walk-in (penggunaan fasilitas dengan durasi maksimal 2 jam) dan konsep independent (penggunaan fasilitas dengan durasi maksimal 6 jam). Sementara untuk pelayanan kelompok diterapkan sistem sewa dengan konsep kelompok 6 orang dan kelompok 8 orang.

Penentuan pelayanan tersebut pada akhirnya menentukan fasilitas yang didapat serta tata letak ruang yang sesuai dengan kegiatan yang dilakukan sesuai dengan pelayanan yang tersedia. Berikut merupakan pengelompokan pelayanan dan fasilitas dengan tata letak dan suasana ruang.

\begin{tabular}{|c|c|}
\hline Jenis Pelayanan & Fasilitas yang di dapat \\
\hline Walk In & Meja Kerja (non komputer) \\
\hline Independent & Membership \\
\hline Kelompok & Meja Kerja (komputer) \\
\hline
\end{tabular}

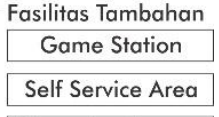

Discussion Lounge

Bagan 2. Konsep Fasilitas dan Pelayanan

\begin{tabular}{|c|c|c|}
\hline Jenis Ruang Keria & Jenis Pelayanan & Jenis Ruang Kerja \\
\hline Touch Down Plan & Walk In & Open Plan \\
\hline Privat Plan & Independent & \\
\hline Team Plan & Kelompok & Work Lounge \\
\hline
\end{tabular}

Bagan 3. Konsep Tata Letak Ruang

\section{Tema}

Konsep perancangan berdasarkan tata letak ruang dan suasana ruang yang telah ditentukan, maka tema perancangan mengusung Workable \& Warm sebagai tagline nya. Workable untuk menciptakan suasana yang produktif, berani, namun tetap santai dan fleksibel. Warm untuk menciptakan suasana kehangatan dalam melakukan kegiatan interaksi dan kolaborasi yang ada pada ruang co-working.

\section{Desain}

Desain memepertimbangkan konsep maupun tema yang telah ditentukan. Konsep dan tema tersebut menciptakan transformasi desain antara lain sirkulasi ruang, material pembentuk dinding, lantai dan plafon serta furnitur yang digunakan pada fasilitas yang disediakan oleh ruang co-working.

\section{Sirkulasi}

Pola sirkulasi pada ruang menggunakan pola sirkulasi linear kemudian menyebar. Sirkulasi ini dapat digambarkan antara lain sebagai berikut.

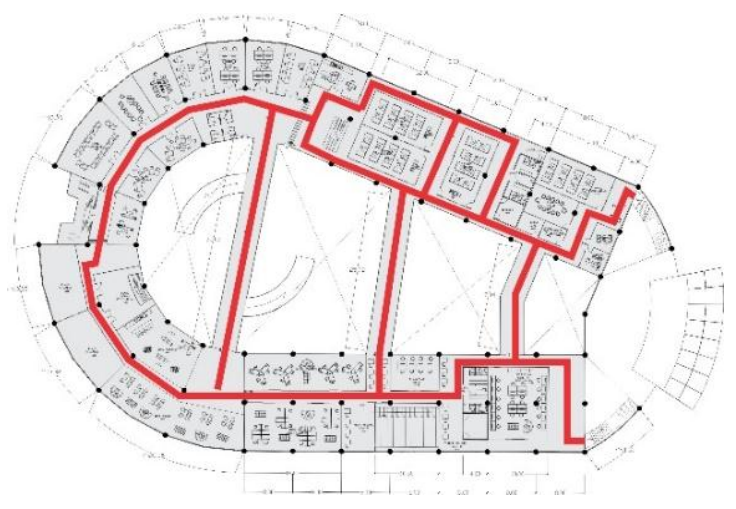

Gambar 5. Pola Sirkulasi 


\section{Pencahayaan}

Konsep pencahayaan yang telah di jabarkan sebelumnya mengidentifikasikan peletakkan jenis lampu yang digunakan pada setiap ruang yang ada pada ruang co-working. Berikut merupakan gambaran titik lampu pada ruang co-working.

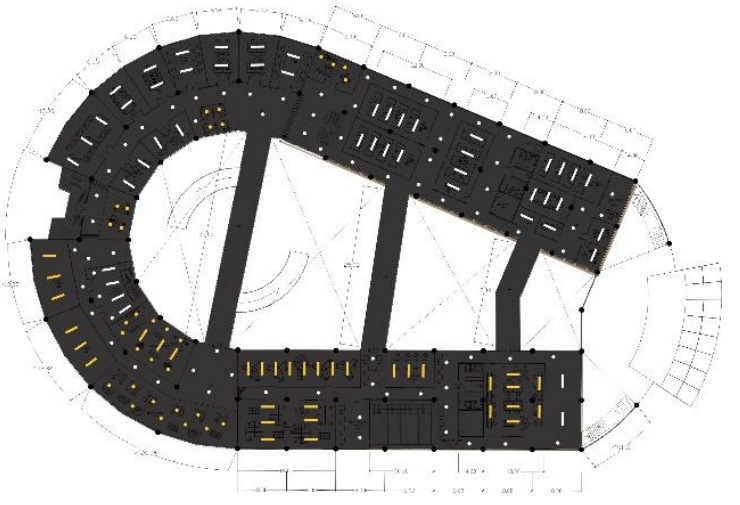

Keterangan:

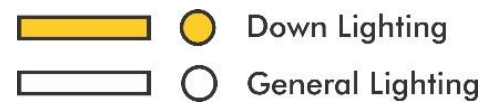

Gambar 6. Titik Lampu

Pencahayaan pada ruang-ruang co-working sebagian besar menggunakan lampu dengan jenis down lighting. Sementara penggunaan jenis lampu general lighting digunakan pada ruang-ruang dengan tingkat fokus yang tinggi seperti ruang pertemuan dan ruang-ruang kerja pengelola. Selain itu, general lighting juga digunakan untuk penerangan sirkulasi.

\section{Warna}

Warna yang digunakan pada ruang-ruang coworking menyesuaikan tema yang telah ditentukan berdasarkan pertimbangan warna yang telah dijabarkan sebelumnya.

a) Warna Dinding

Warna dinding merupakan warna yang menyegarkan. Pada dinding, perpaduan warna yang kontras juga dapat mempengaruhi persepsi seseorang untuk produktif dalam melakukan sesuatu. Perpaduan warna gelap terang akan membantu produktivitas kegiatan pengguna.

b) Warna Plafon

Warna plafon yang digunakan merupakan warna gelap dengan perpaduan warna hangat. Hal ini akan menciptakan persepsi bahwa ruang yang digunakan merupakan ruang informal sehingga pengguna tidak terlalu kaku dalam menggunakan fasilitas yang ada di dalamnya.

c) Warna Lantai

Warna lantai merupakan warna yang bersifat hangat agar pengguna dapat merasa lebih akrab dengan ruangan yang digunakan. Selain itu, lantai dengan sifat yang hangat dapat mempengaruhi keakraban pengguna dalam berkolaborasi.

\section{Material}

a) Lantai

Material dasar pada ruang co-working merupakan beton ekspos yang telah dilakukan finishing. Pada area fokus dan area sharing menggunakan lantai parquet kayu sehingga beton ekspos merupakan material lantai untuk sirkulasi. Sementara untuk material kantor pengelola menggunakan bahan keramik.

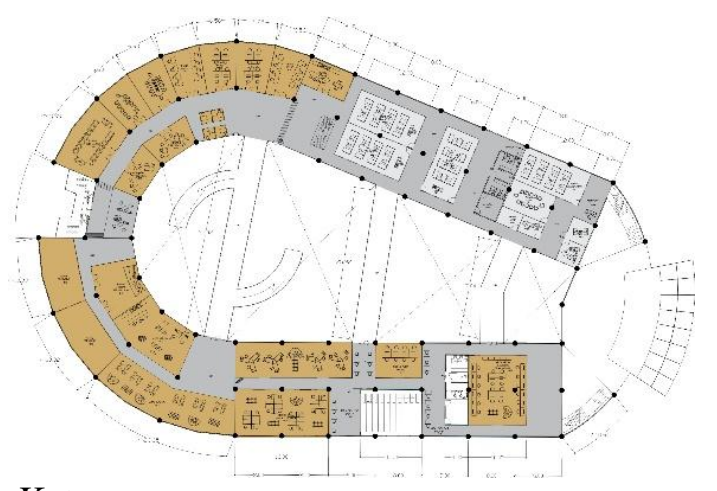

Keterangan:

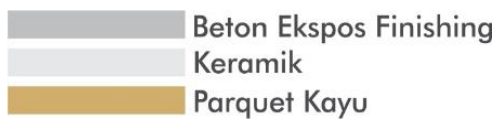

Gambar 7. Mterial Lantai

b) Plafon

Plafon pada ruang co-working menggunakan plafon tripleks pada ruang sharing dan ruang pertemuan. Sementara untuk ruang-ruang fokus bekerja menggunakan plafon waffle dengan material kayu. 


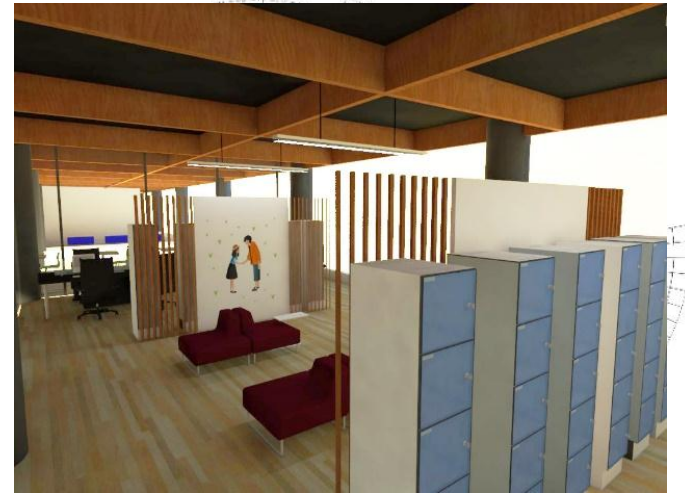

Gambar 8. Material Plafon

c) Dinding

Material dinding yang digunakan pada area co-working merupakan material yang sebagian besar merupakan partisi karena sebagian besar ruang merupakan ruang dengan tata letak open plan. Material partisi yang digunakan diantanya dinding kaca, dinding kisi-kisi kayu dan partisi tripleks dengan finishing. Penggunaan dinding kaca digunakan pada ruang-ruang yang memiliki tingkat fokus sedang, sementara untuk tingkat fokus yang tinggi menggunkan patisi triplek dengan finishing. Penggunaan dinding kisi-kisi kayu digunakan pada area fokus sedang dan area sharing. Ketiga material tersebut juga dikombinasikan pada satu ruang. Pada area sharing, terdapat beberapa ruang yang tidak menggunakan dinding sebagai area diskusi yang terkspos.

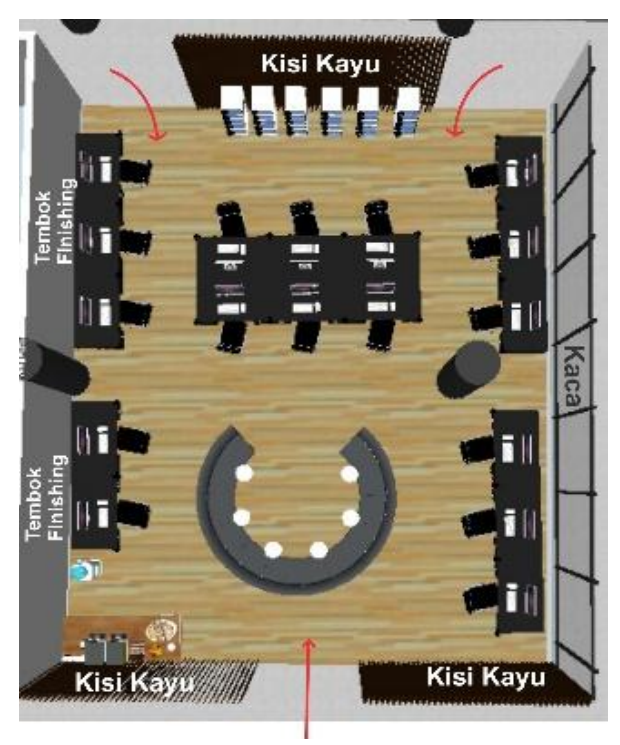

Gambar 9. Dinding Area Kerja Individu

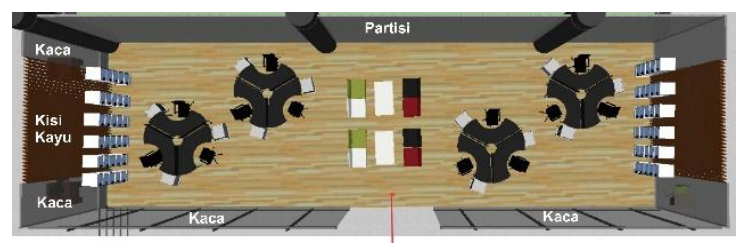

Gambar 10. Dinding Area Kerja Kelompok Kelipatan 3

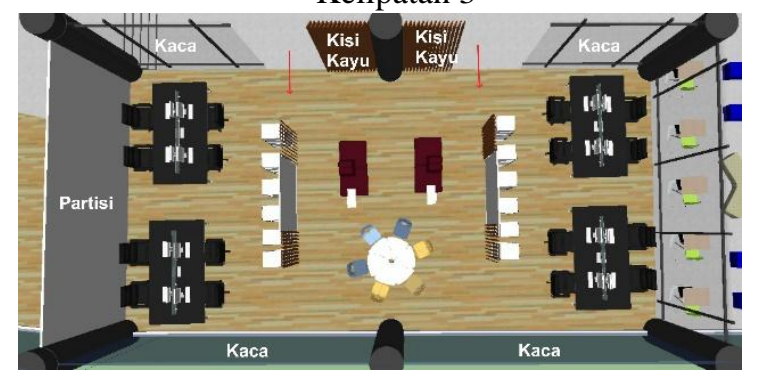

Gambar 11. Dinding Area Kerja Kelompok Kelipatan 4

\section{Perspektif}

Hasil dari desain pada setiap elemen ruang dan perabot interior yang ditata sesuai dengan kebutuhan, menghasilkan perspektif ruang sebagai berikut.

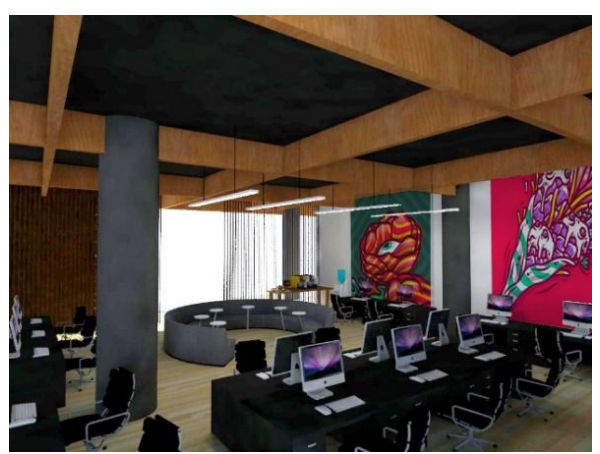

Gambar 12. Perspektif Area Kerja Kelompok Kelipatan 3

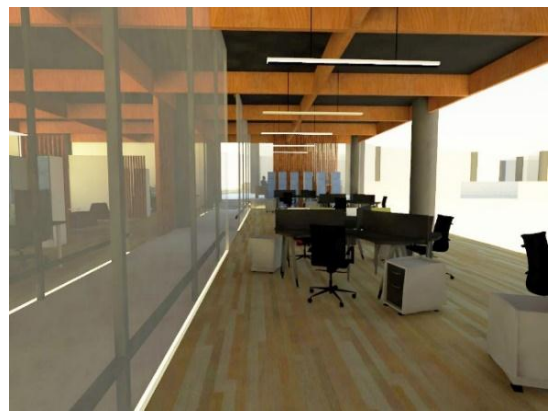

Gambar 13. Perspektif Area Kerja Kelompok Kelipatan 4 


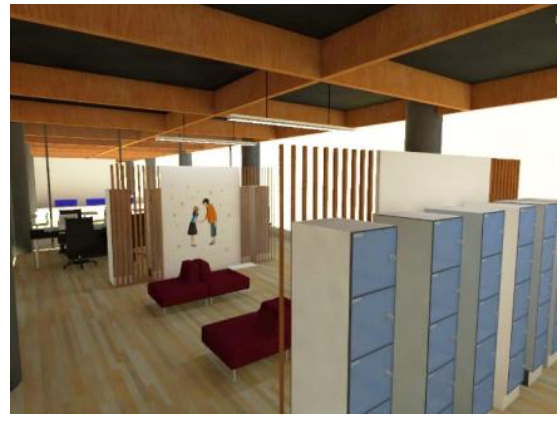

Gambar 14. Perspektif Area Kerja Individu

\section{KESIMPULAN}

Terbentuknya Badan Ekonomi Kreatif di Indonesia merupakan sebuah deklarasi bahwa kreativitas merupakan hal yang berpengaruh dalam perkembangan ekonomi negara pada era milenial saat ini. Adanaya sarana co-working sebagai bagian dari Pusat Komunitas di Purwokerto merupakan suatu dukungan dalam mengembangkan kegiatan kreatif masyarakat Indonesia. Area co-working memberikan kesempatan bagi setiap orang yang ingin mengembangkan produktivitas dan kreativitas tanpa harus memiliki kantor.

Kolaborasi dan saling bertukar pengetahuan merupakan kegiatan yang terjadi pada ruang co-working dan tidak terjadi pada sebuah kantor formal. Bertemu dengan rekan baru dengan latar belakang yang berbeda menjadikan seseorang dapat memiliki hubungan baru dan bahkan menciptakan karya baru.

Pengembangan sarana-sarana kreatif di Indonesia menjadi hal yang diperhitungkan saat ini. Purwokerto sebagai kota berkembang, tidak luput dari sasaran pembangunan saranasarana kreatif. Kegiatan maupun kompetisi kreatif telah diupayakan oleh pemerintah daerah. Ini membuktikan, perkembangan kreativitas masyarakat perlu ditampung dan dikembangkan.

Pelayanan, tata letak dan suasana ruang adalah faktor yang sangat mempengaruhi kegiatan yang dilakukan oleh para penggiat kreatif. Dengan konsep ruang open plan office, pengguna dapat dengan mudah berinteraksi dan bertukar pikiran dengan lebih banyak pengguna dari berbaga latar belakang. Mengusung tema workable and warm, menciptakan sebuah ruangan yang berani dan optimis dengan menggunakan warna-warna gelap dan terang. Penggunaan material kayu ekspos menjadikan suasana interaksi sosial yang hangat.

\section{REFERENSI}

Bekraf. (2017). Data Statistik dan Hasil Survei Ekonomi Kreatif. Kerjasama Badan Ekonomi Kreatif Dan Badan Pusat Statistik.

Garrett, L. E., Arbor, A., \& Spreitzer, G. M. (2014). 10.5465/ambpp.2014.139.

Hidjaz, T. (2011). Interaksi Perilaku dan Suasana Ruang di Perkantoran Kasus di 2 lokasi Kantor Pusat PT . Telkom , Bandung. Jurnal Iternas Rekarupa, 1(1), 13-27.

Hidjaz, T., \& Interior, P. D. (n.d.). Terbentuknya Citra Dalam, 51-65.

Marcelina, A., Ardana, I. G. N., Yong, S. De, \& Siwalankerto, J. (2016). Perancangan Interior Co-Working Space di Surabaya, 4(2), 781-789.

Paper, C. (2016). Urban Co-working Space: Creative Tourism in Digital Nomads Perspective Urban Co-working Space: Creative Tourism in Digital, (August).

Soediono, B. (2015). Building Community Through Co-working: a Case Study of Spatial Factors Affecting Member Satisfaction With Coworkspaces and Collaborative Activity a. Journal of Chemical Information and Modeling, (August), 160. https://doi.org/10.1017/CBO9781107415 324.004

Spinuzzi, C. (2012). Working Alone Together: Co-working as Emergent Collaborative Activity. Journal of Business and Technical Communication, 26(4), 399441. https://doi.org/10.1177/10506519124440 70

Wicaksono, A. A., \& Tisnawati, E. (2014). Teori Interior. Retrieved November 1, 2017 , from https://books.google.co.id/books?id=03r QBgAAQBAJ\&pg=PA28\&dq=sanitasi+ adalah\&hl=en\&sa $=X \&$ redir_esc $=y \# v=$ on epage $\& \mathrm{q}=$ sanitasi adalah $\& \mathrm{f}=$ false 